\title{
Ethnic Variations in Young Adults Living at Home
}

\section{Monica Boyd}

Department of Sociology

Florida State University

Tallahassee, Elorida

\section{Abstract}

Logistic regression analysis of 1991 Canadian census data shows that age and ethnic origin group are the two most important factors underlying the varying propensities of single young adults age 20-34 to live in the parental home. Highest percentages of young adults, both men and women, living at home are found for those declaring Greek, Italian, Balkan, Portuguese, South Asian, Chinese, Other East-Southeastern Asian, Arab and West Asian, and Jewish ethnic origins. In many of these groups, either women are more likely than men to live at home or gender differentials are small.

\section{Résumé}

Une analyse de régression logistique des données du recensement canadien de 1991 révèle que l'âge et l'origine ethnique sont les deux facteurs principaux sous-tendant les propensions variables des jeunes célibataires de 20 à 34 ans à vivre au domicile parental. Les pourcentages les plus élevés se trouvent chez les jeunes - hommes et femmes - se déclarant de parents grecs, italiens, balkaniques, portugais, sud-asiatiques, chinois, issus d'autres pays de l'Asie de l'est ou du sud-est ou d'origine juive. Dans la plupart de ces groupes, les femmes ont plus tendance que les hommes à rester chez leurs parents ou l'écart entre les sexes est faible.

Key words: cluttered nest, living arrangements, ethnicity, co-residency 


\section{Introduction}

During the past two decades, social scientists, the media and the public at large have expressed keen interest in the "cluttered nest." In the 1980s and 1990s, North American researchers produced dozens of studies on the phenomenon of young adults remaining in, or returning to, parental homes. At least one journal devoted an entire issue to the theme (Journal of Family Issues, 1997), and the subject also was profiled in review essays appearing in the Annual Review of Sociology and elsewhere (White, 1994; also see Goldscheider and Goldscheider, 1994 and Ward and Spitze, 1992). Concomitantly, newspapers and television covered the topic, often portraying adult children living with parents as a problem in need of a solution (Grigsby, 1989; also see Hartung and Sweeney, 1991). In the closing months of 1995 , the implied negatives of young adults living at home resurfaced with the re-issued Doonesbury cartoon strip "Zonker returns home" vignettes which originally appeared in 1991.

This widespread interest in young adults living with parents reflects both empirical trends and conceptual models of familial change. Empirically, temporal fluctuations exist in the percentages and numbers of North American young adults co-residing with parents, thus creating impressions of behavioral shifts for those actually experiencing co-residency and inviting explanations from social scientists (Boyd and Pryor, 1989b; Boyd and Norris, 1995a: Table 1; Boyd and Norris, 2000; Goldscheider and Goldscheider, 1994; Goldscheider, 1997; White, 1994). For example, between 1971 and 1981, the percentage living with parents declined for single adults in Canada who were between 15 and 34 years old, following a more general twentieth century pattern of non-family living. But, the percentage living with parents rose for these young adults between 1981 and 1986. Percentages remained relatively stable - and in some instances declined - between 1986 and 1991 for young adults grouped into five year age categories (Boyd and Pryor, 1989b; Boyd and Norris, 1995a: Table 1). Despite this stability in the percentages living at home between 1986 and 1991, numbers at home were larger by 1991 as a result of the increased numbers of young adults, produced by the aging of the baby boom cohorts. The more intuitive and flamboyant story produced by increased numbers diverted attention from stable and then declining "rates" over time (Boyd and Norris, 1999, 2000), and it stimulated media and academic discussions on changes in the transition to adulthood and on inter-generational relationships.

In addition to temporal variations, two theoretical reasons motivate social science interest in the topic of young adults living at home. First, co-residency and its implied opposite -independent living - are important indicators of phases in the transition to adulthood (Settersten, 1998; White and Rogers, 1997). Second, the "modernization" perspective on families in industrial and postindustrial societies theorizes a decline in the centrality of the family in peoples' lives (familism) and thus in multi-generational co-residency (Glick, Bean and 
Van Hook, 1997; Goldscheider and Goldscheider, 1989a: 185-192; 1993a: 3637). Persisting or actual increases in young adults living at home challenge the modernization perspective on family changes, including the decline of familism.

An additional challenge arises from an implied corollary of modernization/ industrialization, notably homogeneity. The evolution of the nation state, the creation of mass consumer markets and the development of mass communication systems are viewed as producing and inculcating universal values and outlooks. One expected consequence is increased homogeneity of the desires and behaviors of young adults with respect to non-familial living arrangements. Yet, as observed by Goldscheider and Goldscheider (1988: 526), subgroups in a population can have quite different levels of residential independence for their young unmarried adults, and in levels of parental-child co-residency.

Such variations generate two questions: 1) do young adults from different social groups differ in the propensity to live with parents; and 2) if yes, how can such patterns be explained theoretically? United States research finds considerable ethnic and racial variation in the expectations and behaviors of young adults regarding parental co-residency (Burr and Mutchler, 1993; Christian, 1989; Goldscheider and Goldscheider, 1988; 1989a; 1993a, 1993b; Hernandez, 1989; Kanjanapan, 1989; Kobrin and Goldscheider, 1982). Such variations are consistent with the argument that the decline of familism is neither universal nor inevitable, even within "modern" societies (see Goldscheider and Goldscheider, 1989; 1993a). Left largely unexplored are differences between groups of young Canadian adults who are members of different ethnic origin groups. Analysis presented in this paper finds substantial differences between Canadian ethnic origin groups in the propensity of young adults to live with parents. The investigation begins with a review of the theoretical underpinnings of ethnic origin variations in parental-child co-residency. Ethnic variations in the propensity of young adults in Canada to live with parents then are analyzed, using individual records from the 1991 census public use micro-data file. Logistic regression analysis confirms that ethnic origins are important factors influencing levels of parental-young adult co-residency in Canada today.

\section{Factors Influencing Young Adults Living with Parents}

Sociological explanations for why young adults live - or do not live - in the parental home stress variations in economic resources, constraints and preferences (Goldscheider and Goldscheider, 1989a: 185-193; Kobrin and Goldscheider, 1982:104-105; Hernandez, 1989:20).

Separate residences for young adults and their parents require that both parties have the financial revenues necessary to rent or purchase separate housing. Reflecting interest in young adults, in the school-to-work transitions, and an underlying assumption that parents are likely to be employed, much of the 
literature emphasizes the economic resources of young adults. Studies note that rental or purchasing options for separate dwellings may not exist for impoverished young adults whose finances may constrain them to reside with parents or others (Boyd and Pryor, 1989a; Goldscheider, 1997; Haurin, Haurin, Hendershott and Bourassa, 1997). As well, the residential location of young adults is influenced by the extent to which co-residence with parents represents financial advantages (DaVanzo and Goldscheider, 1990: 243-244; Wister, Mitchell and Gee, 1997). When living together, parents and off-spring can share resources, experience economies of scale with respect to food, and shelter costs (Grigsby, 1989:296), and assist with emotional support and household tasks (Veevers and Mitchell, 1998).

The availability of a parental home often is assumed in discussions of whether or not young single adults reside in the parental home. However, demographically induced constraints on living with parents exist when the parental home is unavailable for co-residency as a result of separation, divorce, mortality and/or migration. Marital dissolution is associated with changes of residence for at least one parent. When a parent also undertakes a long distance geographical move, separation and/or divorce may remove a parental home from immediate access. Conflict during divorce or remarriage of one or both parents also can create incentives for young adults to leave home altogether. An analysis of the 1990 General Social Survey found that young adults are more likely to be living at home if both parents are still living together than if they are not. As well, young adults are less likely to be living with a parent if that parent has remarried (Boyd and Norris, 1995b. Also see: Goldscheider, 1997; Mitchell, 1994, 1998; Mitchell, Wister and Burch, 1989).

Additional constraining factors arise from death and migration. Parental death may mean that the parental home may not be available or that the remaining living parent downsizes living accommodation, making co-residency more inhospitable. Finally, migration and the age at which it occurs affects the availability of parents for co-residency. Although the implications are not well spelled out, types of international migration (refugee, economic or family reunification) should affect child-parental co-residency given the association between migration type, the composition of the flow, and the possibility that family migration is more likely to reflect established family networks between countries of origin and destination than holds for humanitarian or economic based flows (Glick, Bean and Van Hook, 1997). Age at immigration also is associated with the presence or absence of parents available for co-residency. Young adults who immigrated to Canada as children almost always migrate with parents, but this is less certain for immigrants who arrive as young adults (Boyd and Norris, 1995a: Table 2; Boyd and Norris, 1996).

As factors that facilitate or retard young adult-parental co-residency, economic resources and constraints are implicated in the modernization perspective of family change. The emergence of industrial and post-industrial societies has 
been accompanied by rising standards of living and increasing education, both of which should increase the economic resources available to young adults and their parents for separate residences. As a process, industrialization also has both caused and facilitated substantial internal and international migration, thus potentially diminishing the availability of parental homes as sites of residence for young adult offspring. Other demographic correlates have been increases in longevity and in divorces, the former potentially increasing, and the latter potentially diminishing, the availability of parental homes for co-residency. Taking together, one implication of these changes is that over time the percentages of young adults living with parents should decline, an expectation generally supported by twentieth century trends in Canada and the United States (Boyd and Pryor, 1989a, 1989b; Goldscheider and Goldscheider, 1994; White, 1994). A second implication, however, is that at any one point in time, variations within populations with respect to economic resources and constraints should be associated with variability in young adult-parental-co-residency-levels.

Economic resources and constraints are conditional variables that diminish or enhance the likelihood of young adults living at home. Preferences for living arrangements, however, are also important influences. Indeed, preferences are key concepts in the theoretical model that links familism to variations in young adult living arrangements (Kobrin, 1978; Kobrin and Goldscheider, 1982; Goldscheider and Goldscheider, 1988; 1989a, 1989b, 1993) and ultimately to ethnic origin variations in young adult-parental co-residency patterns.

\section{Familism and Preferences}

The term "familism" implies that family roles and relationships are at the core of peoples' lives (Goldscheider and Goldscheider, 1993). This centrality of family relationships is closely associated with the concept of family solidarity, which refers to familial social relations that include exchange, affective closeness, interaction, normative obligations and value consensus (White and Rogers, 1997). This matrix of social interaction, normative expectations and shared values influences the living arrangement preferences of the young and old alike, emphasizing the desirability of inter-generational co-residency. However, according to the "modernization" perspective of family change, social and economic transformations over time have reduced the centrality of the family and de-emphasized family loyalties, values and influences. The weakening of familism means declining importance of relationships with extended family members and attenuation within the nuclear family of the influence of parents over children (Goldscheider and Goldscheider, 1993a; also see Chekki, 1988 for a case study). Such changes imply diminished preferences for co-residency between parents and adult children.

Located within a model of historical change, the decline of familism and altered preferences for co-residency is relevant for examining temporal shifts in living 
arrangements. However, change is not monolithic. If modernization has reduced the centrality of the family and de-emphasized family loyalties, values and influence, it has been an imperfect vehicle of change. Within contemporary society at any given time, some groups continue to emphasize family and familial orientations and to have preferences for inter-generational co-residency (Glick, Bean and Van Hook, 1997; Goldscheider and Goldscheider, 1989a, 1989b; 1993a, 1994; Hernandez, 1989; Kanjanapan, 1989). Such variations and the derived preferences for living arrangements in turn produce different patterns of parental-young adult co-residency for groups demarcated by ethnicity.

At least two factors are thought to account for the persistence of familism among select ethnic groups. First, some groups are recent arrivals, and they bring with them the culture and patterns of family loyalty found in their countries of origin (Burr and Mutchler, 1993; Glick, Bean and Van Hook, 1997; Goldscheider and Goldscheider, 1993a: Chapter 4; Kanjanapan, 1989). Second, continued use of the original language and high levels of ethnic/racial residential concentration in North America increases the exposure of individuals to members of their ethnic/racial groups (Goldscheider and Goldscheider, 1993a). As a result of the greater intensity of ethnic/racial based interaction, the centrality of family roles, values and obligations may be maintained for select ethnic and racial groups. In such circumstances, the values and preferences of parents and young adults will favor young unmarried adults living at home. To the extent that preferences translate into behavior, the implication is that levels of young adult-parental co-residency will vary across ethnic groups. To date, research suggests that high levels of young adults will reside in the parental home for Mexican, Hispanic and Asian ethnic origin groups in North America (Burr and Mutchler, 1993; Chekki, 1998; Goldscheider and Goldscheider, 1993a; Hernandez, 1989; Kanjanapan, 1989; Zhou and Bankston, 1994). The "Southern Mediterranean" family system with its emphasis on the centrality of the family (Guerrero and Naldini, 1996; Noivo, 1997) implies also high levels of young adult-parental co-residency in North America for these groups, as has been the case in Italy and elsewhere (Rossi, 1997). By comparison, young adults from Northern European ethnic origin groups should display lower levels of co-residing with parents.

Linking familism to preferences offers a theoretical explanation for observed ethnic variations in young adults living with parents. Familism also is associated with gender roles, eliciting gender specific preferences for young adult-parental co-residency. Possible gender role consequences of familism are threefold: 1) gender role differentiation is strong; 2 ) the centrality of women in home life is emphasized; and 3) offspring are expected to marry within a reasonable time after attaining adulthood. These gender role prescriptions suggest that where familism - the centrality of family - is strong, preferences may be stronger for the co-residency of unmarried female offspring than for unmarried male children (Goldscheider and Goldscheider, 1993a). One implication is that young 
unmarried women from ethnic or racial groups characterized by higher levels of familism are more likely than young men to live with parents. At the least, this argument suggests that high levels of young women co-residing with parents should be observed for young adults with Asian, Latin American, and Southern European ethnic origins.

\section{Data and Research Design Issues}

In emphasizing preferences, constraints and resources, previous studies of the "cluttered nest" provide the conceptual underpinnings for understanding why levels of parental-young adult co-residency in Canada should vary by ethnic origins, and by social, economic and demographic characteristics. These variations are examined with data from the 1991 Census Public Use Microbat File (PUMF) on Individuals. This file is derived from the original $20 \%$ sample which responded to the 2B 1991 census form. In size, the PUMF of individuals represents a 3 percent sample of the 1991 Canadian population. The following discussion indicates the limitations of this database, but also notes its advantages.

The disadvantages associated with using the 1991 PUMF data are those arising from all census derived public use data in Canada. The Canadian census asks numerous questions but lacks many questions on any one topic. This has three implications for a census based study of young adults living at home. First, the census instrument records only the presence of young adults and their relationships to other household members. No information is collected on whether young adults residing with parents are continuous nesters (having never left home) or returnees. A study of young adults in Vancouver found that age 21 is the desired home leaving age (Veevers, Gee and Wister, 1996: Table 2). Coupled with increasing later ages at marriages, this home leaving norm suggests that most young adults in their early twenties have never left home, while those in their mid-twenties and older will include returnees (also see: Settersten, 1997).

Second, information on parents is lacking for young adults not living at home. The census collects information about each respondent in a given household on a de jure basis. It does not ask family of origin questions of young adults who may be living away from their parent(s). Even where there is information about parents (collected when the parent(s) and young adults co-reside), the arrangement of the publicly released database files hampers an effective use of information on both parents and offspring in Canada. Unlike the hierarchically arranged U.S. census files which permit linking family and individual characteristics, three separate, independent files (individual, family, and household) exist in Canada. The Public Use Sample file of individuals contains information primarily about respondents' characteristics, along with a small amount of data on housing and on household and family size and type. Family 
and household public databases do contain information about household members. But they have three drawbacks that severely limit analyzes on young adults living at home: 1)available data do not always permit easy capture of young adults in the parental home; 2) the amount of socio-demographic information is small compared to the PUMF of individuals; and 3) data on most variables, including ethnic origins, are substantially aggregated into a few categories, thus limiting analysis.

The existence of only one indicator of ethnicity is the third limitation of the 1991 PUMF database. Conceptual underpinnings for co-residency variations by ethnic groups emphasize ethnic based interaction. Yet, direct measures of ethnic interaction are lacking in virtually all the North American data sets used to analyze the propensities of young adults to live with parents. Even the seminal work of Goldscheider and Goldscheider relies on measures of residential concentration and use of non-English (derived from multiple questions on the context of use - such as school, home, work, friends) to indicate intensity of ethnic interaction. Census data are especially devoid of explicit measures of ethnic group interaction or intensity. In the Canadian 1991 census, only one question on ethnic or national origin ancestry is asked (To which ethnic or cultural group(s) did this person's ancestors belong?). Further, responses often are aggregated on the Public Use Microdata files, masking ethnic distinctions that exist in many regions of the world.

It is worth noting that language questions in North American censuses also are not well suited to serve as alternative or supplementary measures of ethnic intensity. The Canadian census has three language questions: knowledge of English and/or French; home language and mother tongue. The question on knowledge of official languages lacks the detail to be a strong indicator of ethnic intensity for non-Anglo/French ethnic origin groups, Methodological considerations caution against using additional census-derived information on home language or mother tongue as substitute measures of ethnic intensity in analyses of parent-child co-residency. With cross-sectional data, the assumption that language spoken in the home influences parental-child co-residency is questionable. Causality can run in the reverse direction with living arrangements shaping responses to the language question. Young adults who live alone or with non-relatives may not be in living arrangements where it is possible to use home languages other than English nor French. The census question on mother tongue refers to language first spoken and still understood. As with home language use, retention or atrophy in mother tongue language can be a consequence of living arrangements rather than an indicator of intense ethnic ties that influence young adult-parental co-residency.

Despite the absence of multiple indicators of ethnicity or acceptable substitutes and the limitations of aggregated categories, census data on ethnic origin remain popular sources of information on variations in ethnic group behavior. Studies of the "minority group fertility" model routinely use ethnic origins as proxies for 
ethnic group interaction. So do studies on living arrangements (see: Burr and Mutchler, 1993; Christian, 1989; Hernandez, 1989; Kanjanapan, 1989). The pervasive use of census data is understandable given the difficulty of enumerating small ethnic groups through other surveys and the problems of sampling variability for even the larger groups in these surveys.

Indeed, information on many ethnic origin groups is one of the two major advantages in using data from the 1991 PUMF of individuals. Sheer size and near universal census coverage permit an analysis of parental-young adult coresidency for many more ethnic groups than would be possible with smaller, and possibly geographically restricted, surveys. A second advantage is the wealth of socio-economic and demographic characteristics collected by the Canadian census. While important in their own right as determinants of young adults living with parents, socioeconomic and demographic factors also may underlie variations by ethnic origin. As Goldscheider and Goldscheider (1989a: 192) observe, what are "ethnic effects" often are difficult to disentangle. Theoretically, variations should reflect differences in preferences and in familism. However, ethnic groups also often differ in constraints and resources. Performing multi-variate analyzes permits disentangling these intertwined effects of constraints, resources and ethnic origins, as well as statistically controlling for the influence of other variables known to influence living arrangements.

What variables might be included in such a "disentangling" exercise? Obviously, indicators of economic resources and variables measuring demographic constraints also are important candidates for inclusion in a multi-variate analysis of young adults living at home. Level of personal annual income, labor force activity and school attendance are chosen as important economic resource variables in predicting whether or not young unmarried adults lived with parents (Boyd and Pryor, 1989a, 1989b; Boyd and Norris, 1995a).

As noted earlier, young adults without parents are obviously constrained to nonparental living arrangements. The Canadian census does not ask retrospective family of origin questions, so information is lacking on parental deaths, divorce and blended families. However, data do exist on birthplace and timing of immigration. Young adults who have moved to Canada as youngsters are quite likely to have immigrated with parents. In contrast, persons immigrating as young adults, particularly over the age of 20 are not likely to migrate with parents. Most of the latter will be moving on their own and parental coresidence will not be an option. Constraints related to age-at-immigration are held constant in this study by restricting the foreign-born population to those young adults who immigrated before the age of fifteen.

Three additional variables are included in the empirical analysis of parentalyoung adult co-residency. Age composition is important to include as a control variable in any analysis. Research documents that living with parents declines 
with age thus creating the possibility that young adult-parental co-residency differences between ethnic origin groups reflects inter-group differences in age composition. Census metropolitan residence also is included. Smaller areas may lack the alternative housing required or desired by young adults who seek to live away from home (Boyd, 1996b; Boyd and Norris, 1995a; Boyd and Pryor, 1989a, 1989b). Because ethnicity and religion are often statistically correlated, religion also is included as a control variable when examining the net effects of membership in ethnic origin groups.

Conceptual and methodological considerations underlie the decision to focus on those young adults who are age 20-34, who are single (never-married), who are childless, and who are living in all regions of Canada excluding the Atlantic provinces and the territories. The population age 20-34 is studied for two reasons. First, most single women and men between 15-19 years of age in fact are living with parents (Boyd and Norris, 2000). Second, from a life course perspective, "older" young adults deviate from norms about the appropriate age of home leaving and norms about the sequences of stages in the transition to adulthood (see: Settersten, 1998; Veevers, Gee and Wister, 1996). The theoretical framework that connects familism to preferences also suggests that the fullest expression is to be found among the single population rather than the currently married (legal or common-law) or previously married. Certainly, compared to single young adults, the latter two groups are much less likely to be living with parents (Boyd and Norris, 1999; 2000).

Methodological considerations further restrict the population studied to those living in areas outside the Atlantic provinces and the territories. These latter geographical areas are omitted because the aggregation of ethnic groups on the 1991 Public Use Micro Data files for these areas severely reduces the number of ethnic origin groups available for analysis. Methodological considerations also limit the female population to those who have never had a live birth. Although the presence of children appears to deter young adults from co-residing with parents (unpublished tabulations), the effect is not likely to be uniform across all ethnic origin groups. To the extent that ethnic-specific variations exist in norms about premarital sex and pregnancy-related marriages, and in stigmas attached to single offspring raising children, these will influence the propensity of young adults to remain or return home. Because there is no way of determining the existence of such norms or sanctions from census data, these potential effects are minimized in the analysis by removing young never-married women who have born children from the analysis. The 1991 census asked a fertility question only of women, and the same restriction cannot be applied to men. However, most single parents are women, and the impact of having fathered a child on young single adult male-parental co-residencies is likely to be small compared to the impact for young women.

Finally, multiple ethnic origin groups are included in the analysis since they represent over one-third and nearly one-third ( 30.5 percent) of all young women 
and men who were single and childless in 1991. Single origin groups with fewer than 100 women or 100 men on the census data base were aggregated into related summary groups.

\section{Determinants of Young Adults Living at Home}

Of the single young adult Canadian population age 20-34 in 1991, over half were residing with parents. The percentages reflect the diverse impacts of demographic factors, resources and preference-linked factors, defined above. When considered independently from each other (the eta in Table 1, columns 1 and 2), age of young adults, 1990 income, school attendance, ethnicity and religion, are the more important determinants of young adults living at home.

Many of these variables are inter-correlated. For example, the influence of school attendance on living at home exists in part because many school attenders are in their early twenties, and younger adults are more likely to be living with parents than those in their thirties. When statistical adjustments are made for these associations using logistic regression analysis, the relative importance of determining factors changes somewhat. Both the $R$ statistic and the pseudo- $\mathrm{R}^{2}$ show that in a multi-variate analysis, the age of young single adults still is the most important factor explaining young adult-parental co-residencies. However, ethnic origin is the second most important determinant of living with parents for young single women, and the third most important variable (after age and religion) for single men ${ }^{1}$.

\section{Ethnic Origin Differences in Young Adult-Parental Co-residencies}

Three interrelated questions dominate analyzes of ethnic group variations in the propensity of young adults to live at home: 1) what differences in living at home exist by ethnic origins for young adults; and 2) what gender differences exist and do they vary by ethnic origins and 3 ) do the answers to the two preceding questions correspond to those that might be expected from the theoretical links between preferences, familism and young adult-parental co-residency? In addressing the first question, data in Table 2 shows that substantial ethnic origin variations exist with respect to young adult-parental co-residence in Canada in 1991.

Historically, the British and French are the largest groups in Canada although the single responses increasingly are converting to multiple responses as intermarriage occurs and as "Canadian" becomes an option (Boyd, 1996a; 1999). The odds ratios in Table 2 show that relative to the British single ethnic origin group, living with parents is higher for young women and men of French, Polish, Balkan, Greek, Italian, Portugese, Jewish, Arab and West Asian, South Asian, Chinese, other East or Southeastern Asian, or Black single ethnic origins. 


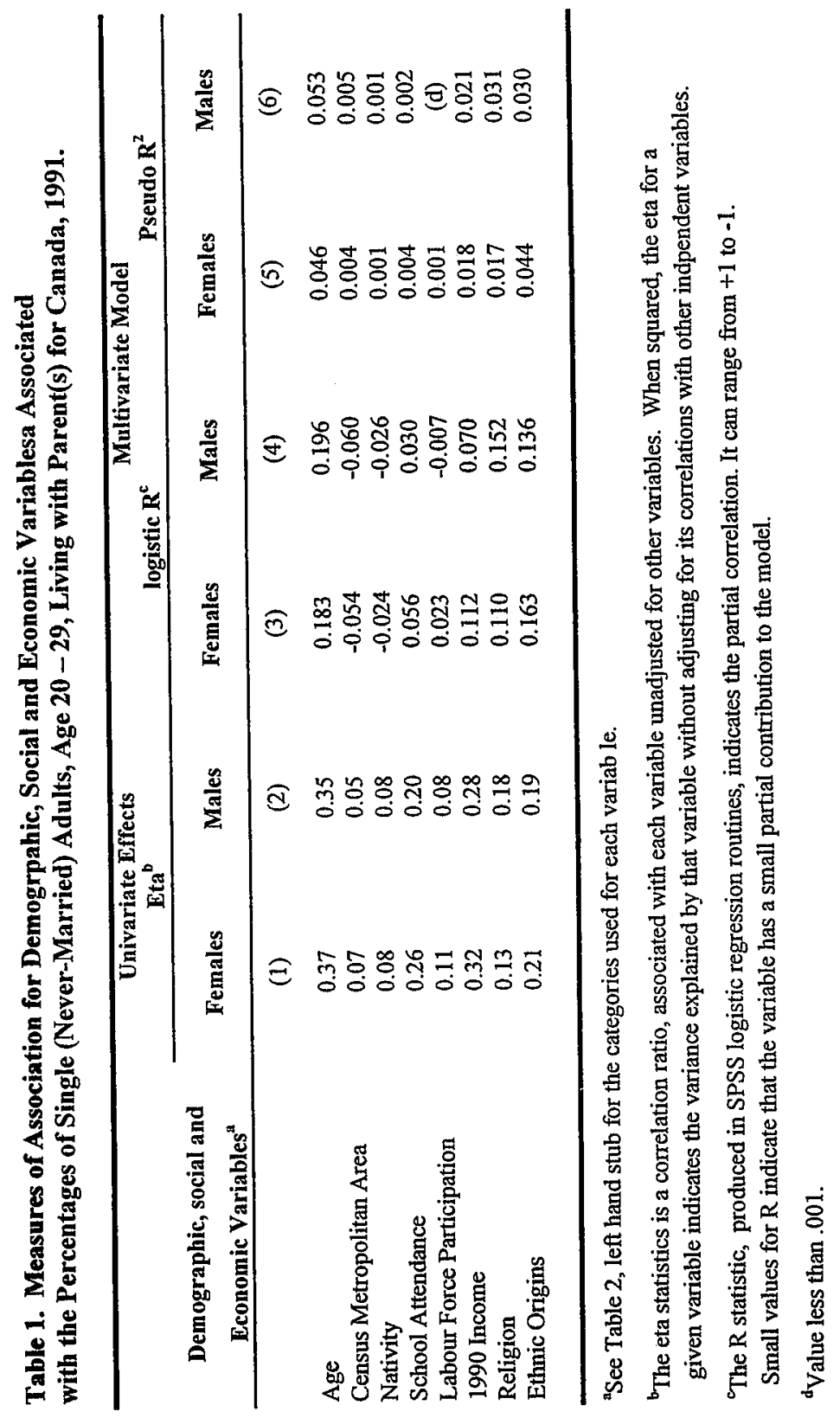


In addition, the odds of living with parents are higher for young men of Dutch and German single ethnic origins compared to that of young men of British ethnic origin. If the overall (unweighted) average is used as the benchmark, the odds of living at home are below this overall average for young men and women of British, French, Dutch, German, Hungarian, Polish, Ukrainian, Black, or Aboriginal ethnic origins and those of other residual single origins and multiple origins. The odds of living with parents are above average for young women and men of Balkan, Greek, Italian, Portuguese, Jewish, Arab and West Asian, South Asian, Chinese, and other Eastern South-eastern Asian ethnic origins. All these odds ratios control for the effects of other variables known to influence the propensity of young adults to live with parents, notably age, nativity, CMA or non-CMA residency, school attendance, labour force participation, 1990 income, and religion (variations in the percentages of young adults living with parents, and the odds ratios for these variables of age, nativity, CMA or nonCMA residency, school attendance, labour force participation, 1990 income, and religion are presented in Boyd, 1998a, Table 2).

Table 3 rearranges the data to show the rank order in living with parents for young adults of various ethnic origin. These rankings highlight the lower propensities to live at home for young adults declaring membership in Northern or Eastern European ethnic origin groups and the higher levels of co-residency for young adults of single Southern European, Asian and Jewish ethnic origins (Table 3, columns 1-4). Persons declaring Aboriginal ethnic origins have the lowest percentages of all groups living in the parental home. High rates of outmigration from reserves and high internal geographical mobility are likely factors underlying these results.

With a few inflections, this pattern of ethnic variations in young adult-parental co-residency holds even when other factors are taken into account, such as religion, school attendance, CMA residence, foreign birth, labor force participation and income (Table 3, columns 5-8). Here the odds ratios found in Table 2 are replaced with the calculated probabilities of living with parents, based on the logit coefficients in Table 2 . When multiplied by 100 , these probabilities can be considered to be "hypothetical chances out of 100 of living with parents." The Spearman rank order correlation between the rankings for the actual percentages and the hypothetical percentages are .962 for young women and .850 for young men, indicating that the ethnic orderings in the tendencies to live with parents are relatively stable, persisting even after other factors are taken into account.

In general, these patterns are consistent with the argument that social groups, demarcated by ethnicity, differ in the normative matrix that increase preferences for young adult-parental co-residency. Although direct measures of social interaction and ethnic intensity are lacking, ethnic origin groups with the highest percentages of young adults living with parents tend to be those characterized by two features: 1) high residential segregation in Canada's major cities and 2) new 


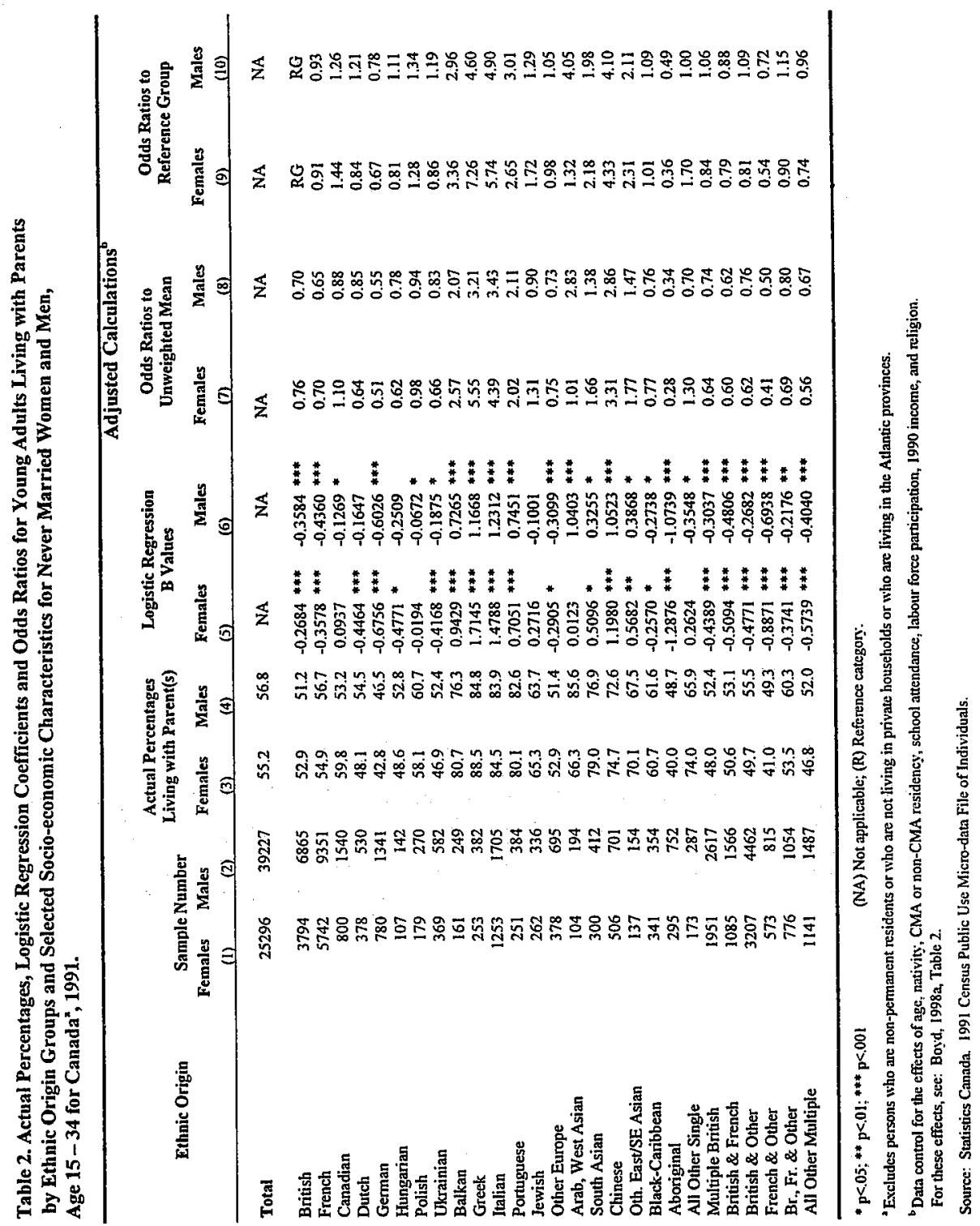




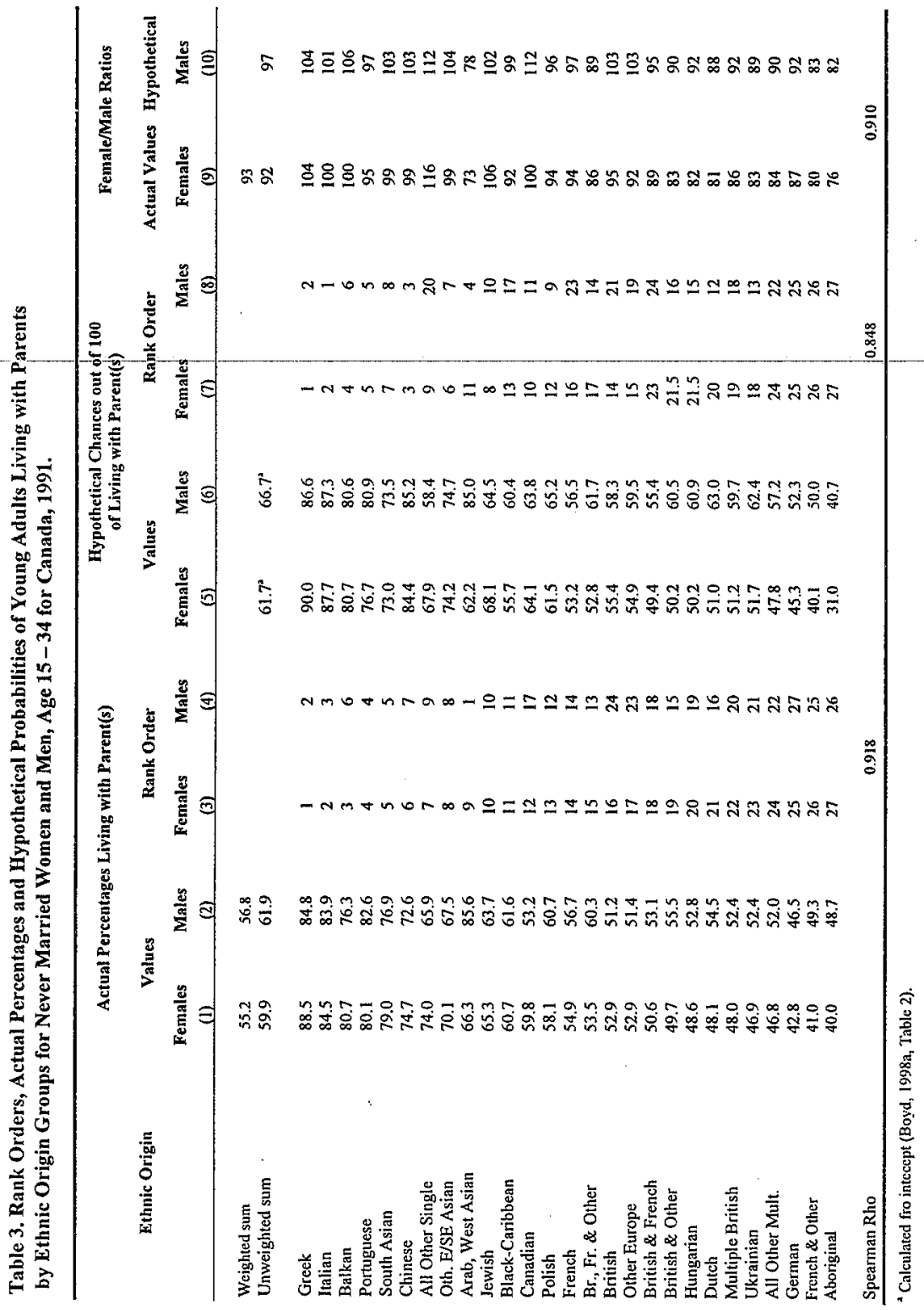


immigrant groups, at least from a post-war perspective. In their analysis of ethnic residential segregation for select ethnic origin groups, Balakrishnan and Hou $(1995 ; 1999)$ find very high ethnic concentration and segregation for Jewish, Chinese, and South Asian groups in 1981 and 1991 in major metropolitan areas, a finding consistent with high ethnic based interaction ${ }^{2}$. As well, many of the groups with the highest percentages of young adults living at home are relatively "new" immigrant groups. Southern European groups arrived in large numbers from the mid-1950s through the 1970s, to be replaced by South Asian, Southeast Asian, Chinese, Arab and West Asian groups during the 1970s and 1980s. Relatively recent arrival implies that these groups may still retain family interaction patterns, expectations, and sanctions that could increase the propensity of single young adults to live at home.

\section{Gender Differences}

One of the corollaries of the familism-preference theorizing is that very strong preferences exist for young unmarried women to live at home for those groups where young adult-parental co-residency is high. Data in Table 3 address this claim. Overall, for every 100 unmarried men age 20-34, 93 unmarried childless women are living in the parental home in 1991. The lower propensity of young women to live with parents compared to young men is found in other studies (Boyd and Pryor, 1989a; Boyd and Norris, 1999). It can be interpreted as one indicator of the decline in familism. Increasingly young women are less likely to adhere to role prescriptions of universal and early marriage and to expect marital roles to take precedence over market-based roles. As well, gender roles and related cost-benefits create dis-incentives for young women to co-reside with parents, and they increase preferences to live independently (Ward and Spitze, 1992: 561-562). However, for some ethnic groups the reverse pattern of living arrangements holds. Women are more likely or just as likely as their male counterparts to live with parents when they report Jewish, Greek, Italian, Balkan, South Asian, Chinese or other East and Southeast Asian ethnic origins or other single ethnic origins (Table 3, column 9).

The hypothetical chances of living with parents take into account the influence of other variables on living arrangements by assuming that young adult women and men share similar characteristics, notably unweighted mean values for age, income and other variables. Under these assumptions, young women are more likely than young men to be living with parents if they declare their ethnic origins to be Greek, Italian, Balkan, Polish, Jewish, Canadian, British, Other European, South Asian, Chinese, other East or South Eastern Asian or if they are in the residual "other single ethnic origin" category. Again, the Spearman rank order correlation of .910 indicates that the multi-variate analysis does not appreciably alter the sex ratio rankings of young adults living with parents for ethnic origin groups. 
The intersection of familism with gender relations implies that those ethnic origin groups which favor young never-married children living at home also exhibit strong preferences for young unmarried daughters remaining in the parental home. This possibility is assessed by calculating Spearman Rho's between the rankings of groups that are high (or low) with respect to young adults living at home and the degree to which the female/male ratio is high or low. The rank order correlations for actual percentages (Table 3, columns 3 and 4) and the rankings of the sex ratios (Table 3, column 9) are .681 for women and .374 for men. The rho's for hypothetical chances (Table 3 , columns 7 and 8 ) and the rankings of the sex ratios (Table 3 , column 10) are .791 for women and .443 for men. The strength of the relationships, particularly for men, is very much affected by the co-residency characteristics of two ethnic origin groups: the Arab and West Asian groups and the "residual" other single ethnic origin group. These two groups exhibit the lowest and highest sex ratios observed for all groups. Because both are composites of other diverse ethnic-origin-groups,-no easy explanation exists for these sex ratios. However, if these two groups are omitted from the rankings, the Spearman rank order correlations for the sex ratios and hypothetical chances rise to .874 for young women and .677 for young men. Overall, the correlations are consistent with the argument that groups that have higher percentages of young adults living with parents also are those favoring the presence of young unmarried women in the home, thus reversing or minimizing the general pattern in which women are less likely then men to be co-residing with parents.

\section{Conclusion}

Three empirical conclusions emerge from this analysis of 1991 census data. First, once adjustments are made for the inter-relationships between variables known to influence young adults living at home, ethnic origins emerge as an important factor influencing levels of young-parent co-residences. Second, rather substantial differences exist between ethnic origin groups in the percentage of young men and women living with parents. Third, ethnic origin differences exist in the extent to which young women are more (or less) likely than young men to be at home. For some ethnic origin groups, there does appear to be an enhanced tendency of young women to live with parents. This tendency is especially true for the Greek, Italian, Balkan, Jewish, South Asian groups, Chinese and other East and Southeast Asian groups. No ready explanation exists for the above average tendency of women of Canadian ethnic origin to be at home compared to Canadian ethnic origin men. This group is a new group, having emerged in the 1991 census, and exhibiting dramatic variability between 1991 and 1996 (the latest census) in regional levels and patterns of response (Boyd, 1996a; Boyd, 1999).

Although the fit is not perfect, the ethnic origin patterns are those suggested by previous North American research emphasizing the role of ethnic group 
differences in familism and in preferences for young adult-parental coresidency. In general, young adults declaring single Northern or Eastern European ethnic origins are less likely to be living in the parental home than are those of Southern European, Asian or Jewish ethnic origins. Many of these ethnic origin groups with higher than average percentages of young adults at home are groups whose membership has grown by recent immigration, and who are residentially concentrated in Canada's large cities.

The findings of this study also highlight two areas in need of greater scrutiny and research. First, census data results suggest that different ethnic groups may vary in the preferences for young unmarried adults residing at home. A team of Canadian researchers have documented age variations in parental-child home leaving norms in Vancouver as has one American study (Settersten, 1998). However, in both countries, small samples and the high cost of larger ones preclude examining ethnic variations in such norms. The Canadian group also investigated the consequences of young adults living at home in terms of parental marital satisfaction, and the satisfaction and well being of parents and offspring alike (Gee, Mitchell and Wister, 1995; Mitchell, 1998; Mitchell and Gee, 1996; Veevers, Gee and Wister, 1996; Veevers and Mitchell, 1998; Wister, Mitchell and Gee, 1997. Their research poses the next round of questions in Canadian and American research on ethnic group variations in young adults living at home: what norms exist in which ethnic groups; are they shared equally by young adults and parents; and are the consequences of co-residency positively perceived, even by ethnic families where normative preferences may be less important than financial considerations.

Two possible outcomes are embedded in such questions. On the one hand, recent studies on the second generation in the United States emphasize the benefits that can accrue to immigrant offspring from ethnic based social networks. Such research suggests both that social relations between family members and social networks between families and ethnic based associations can have positive effects on the educational and health of young adults. From this perspective, young adult-parental co-residency should have positive feedback mechanisms. The centrality of family encourages young adult-parental co-residency which in turn has positive consequences for affective closeness, value consensus and the formation or continuation of ethnic identities (see: Zhou and Bankston, 1994). More generally, co-residency may well represent another mechanism for accessing familial and community resources by ethnic groups that have low levels of human capital or face structural or racially based impediments. On the other hand, White and Rogers (1997) find that offspring report that co-residency does increase the exchange of resources but lowers the affective relationship with parents. Ethnic variations in familism, and in the related interactions and normative consensus between family members may underlie these diverse findings. 
Second, many of the ethnic origin groups with relatively high percentages of young adults at home are groups that have grown through recent immigration. This co-variation is consistent with literature which argues that groups closer in time to non-North American family systems may exhibit high levels of familism, and thus have preferences that result in young adult-parental coresidency. Yet, integration into Canadian society may recast these scripts over time. Subsequent generations of these "new" ethnic groups may well exhibit living arrangements that correspond to those displayed by ethnic groups where immigration histories are in the distant past. In fact, in their analysis of unpublished census tabulations, Boyd and Norris (1996) find that the greater propensity of young women to live with parents holds for the first generation but not for the Canadian-born members of the "new immigrant" ethnic origin groups. Incorporating the dimensions of first, second and third generational status into 1991 census based studies of young adult living arrangements cannot be done, in part because no questions exist on birthplace of parents,_and in part because the public use micro-data files contain very small numbers of nonEuropean ethnic groups for the Canadian born. As a result, the topic of variations in parental-young adult co-residencies by generational status and ethnic origins remains relatively unexplored and awaits future investigation.

\section{Acknowledgments:}

The author thanks Frances Goldscheider and two anonymous CSP reviewers for their helpful comments on an earlier draft.

\section{Endnotes:}

1. It should be noted that one disadvantage of the pseudo $\mathrm{R}^{2}$ is that - unlike the OLS $R^{2}$ - it can never reach a value of one, indicating perfect prediction. Although a corrected pseudo- $\mathrm{R}^{2}$ can be calculated, it provides a good approximation of the OLS $\mathrm{R}^{2}$ only when the dependent variable represents a latent interval scale (Menard, 1995:22). For that reason, corrected pseudo- $\mathrm{R}^{2} \mathrm{~s}$ are not presented in Table 1. However, the conclusions reached from data in Table 1, columns 3-6 are upheld by the corrected pseudo- $\mathrm{R}$ and by the lambda-p values which indicate the proportional reduction of error that occurs when a variable is added to a model. The highest values of lambda-p are found for age, ethnicity, religion and income in the multi-variate models, respectively at .049 , $.034, .019$ and .013 for women and $.053, .026, .036$ and .023 for men.

2. The findings of Balakrishnan and Hou $(1995 ; 1999)$ do not perfectly conform to the pattern observed in Table 3. They also find that segregation indices are high for Aboriginals, for Blacks, and for Ukrainians who live in the Prairie provinces. A lack of exact co- 
respondence can be expected given that their study only examines the CMA populations and examines residential concentration for 12 select ethnic origin groups.

\section{References:}

Balakrishnan, T. R. and Feng Hou. 1999. "Residential Patterns in Cities," in Shiva Halli and Leo Driedger (eds.) Immigrant Canada: Demographic, Economic and Social Challenges. Toronto: University of Toronto Press. Pp. 116-147.

Balakrishnan, T. R. and Feng Hou. 1995. The Changing Patterns of Spatial Concentration and Residential Segregation of Ethnic Groups in Canada's Major Metropolitan Areas, 1981-1991. Discussion Paper No. 95-2, Population Studies Centre, University of Western Ontario, London, Canada.

Boyd, Monica. 1999. "Canadian 'Eh? Ethnic Origin Shifts in the Canadian Census," Canadian Ethnic Studies 31(3): 1-19.

Boyd, Monica. 1998. Birds of a Feather ...: Ethnic Variations in Young Adults Living at Home. Working Paper Series 1998-140. Center for the Study of Population and Demography. Florida State University, Tallahassee, Florida.

Boyd, Monica. 1996a. Constructing Ethnic Responses: Socioeconomic and Media Effects. Working Paper Series 96-133. Center for the Study of Population and Demography. Florida State University, Tallahassee, Florida.

Boyd, Monica. 1996b. Why are Young Adults in Alberta Living At Home? Research Paper No. 1. Lecture Series, Chair of Ethnic Studies Programme in Ethnicity and Population. University of Calgary, Calgary, Alberta.

Boyd, Monica and Doug Norris. 2000, forthcoming. "Demographic Change and Young Adults Living with Parents, 1981-1996," Canadian Studies in Population. (September).

Boyd, Monica and Doug Norris. 1999. "The Crowded Nest: Young Adults at Home," Canadian Social Trends (Spring): 2-5. 
Boyd, Monica and Doug Norris. 1996. Migrating Flocks and Fledglings: Ethnic-Immigrant Variations in Young Adults Living with Parents. Proceedings of the Symposium of the Federation of Canadian Demographers. Ottawa, Canada.

Boyd, Monica and Doug Norris. 1995a. The Cluttered Nest Revisited: Young Canadian Adults at Home in the 1990s. Center for the Study of Population Working Paper Series 95-127. Tallahassee, FL: Florida State University.

Boyd, Monica and Doug Norris. 1995b. "Leaving the Nest: The Impact of Family Structure," Canadian Social Trends. (Autumn): 14-17.

Boyd, Monica and Edward T. Pryor. 1989a. "The cluttered nest:-The living arrangements of the young Canadian adults," Canadian Journal of Sociology 15 (Fall): 462-79.

Boyd, Monica and Edward T. Pryor. 1989b. "Young Adults Living in Their Parents' Home," Canadian Social Trends (Summer): 17-20.

Burr, Jeffrey A. and Jan E. Mutchler. 1993. "Ethnic Living Arrangements: Cultural Convergence or Cultural Minifestation [sic]?" Social Forces 72 (September):169-179.

Chekki, Dana. 1988. "Family in Indian and North America: Change and Continuity among the Lingayal Families," Journal of Comparative Family Studies 19 (Summer): 329-343.

Cherlin, Andrew, Eugenia Scabini and Giovanna Rossi, (Eds.). 1997. "Delayed Home Leaving in Europe and the United States," Special Issue. Journal of Family Issues. Vol. 18 (November).

Christian, Patricia B. 1989. "Nonfamily Households and Housing Among Young Adults," in Frances K. Goldscheider and Calvin Goldscheider (eds.) Ethnicity and the New Family Economy. Boulder, CO: Westview Press. Pp. 57-73.

DaVanzo, Julie and Frances K. Goldscheider. 1990. "Coming Home Again: Returns to the Parental Home of Young Adults," Population Studies 44:241-255.

Gee, Ellen M. Mitchell, Barbara and Andrew Wister. 1995. "Returning to the Parental "Nest", Exploring a Changing Canadian Life Course," Canadian Studies in Population 22(2): 121-144. 
Glick, Jennifer, Frank D. Bean, and Jennifer V. W. Van Hook. 1997. "Immigration and Changing Patterns of Extended Family Household Structure in the United States," Journal of Marriage and the Family 59: 177-191.

Goldscheider, Frances K. 1997. "Recent Changes in U.S. Young Adult Living Arrangements in Comparative Perspective," Journal of Family Issues 18: $645-671$.

Goldscheider, Calvin and Frances K. Goldscheider. 1988. "Ethnicity, Religiosity and Leaving Home: The Structural and Cultural Bases of Traditional Family Values," Sociological Forum 3(4): 525-547.

Goldscheider Frances and Calvin Goldscheider. 1994. "Leaving and Returning Home in 20th Century America," Population Bulletin 48: 2-34.

Goldscheider, Frances K. and Calvin Goldscheider. 1993a. Leaving Home Before Marriage: Ethnicity, Familism and Generational Relationships. Madison, WI: University of Wisconsin Press.

Goldscheider, Frances and Calvin Goldscheider. 1993b. "Whose Nest? A TwoGenerational View of Home Leaving during the 1980s," Journal of Marriage and the Family 55 (November): 851-862.

Goldscheider, Frances K. and Calvin Goldscheider. 1989a. Ethnicity and the New Family Economy: Synthesis and Research Challenges in Frances K. Goldscheider and Calvin Goldscheider (eds.) Ethnicity and the New Family Economy. Boulder, CO: Westview Press. Pp. 185-197.

Goldscheider, Frances K. and Calvin Goldscheider. 1989b. The New Family Economy: Residential and economic relationships among the generations in Frances K. Goldscheider and Calvin Goldscheider (eds.) Ethnicity and the New Family Economy. Boulder, CO: Westview Press. Pp. 1-16.

Grigsby, Jill S. 1989. "Adult children in the parental household: Who benefits?" Lifestyles 10:293-309.

Guerrero, Teresa Jurado and Manuela Naldini. 1996. "Is the South so Different? Italian and Spanish Families in Comparative Perspective," South European Society and Politics 1 (Winter): 42-66.

Hartung, Beth and Kim Sweeney. 1991. "Why Adult Children Return Home," The Social Science Journal 28: 467-480. 
Haurin, R. Jean, Donald R. Haurin, Patric H. Hendershott, and Steven C. Bourassa.1997. "Home or Alone: the cost of independent living for youth," Social Science Research 26 (June): 135-153.

Hernandez, Luis Lazaro. 1989. Nonfamily Living Arrangements Among Black and Hispanic Americans in Frances K. Goldscheider and Calvin Goldscheider (eds.) Ethnicity and the New Family Economy. Boulder, CO: Westview Press. Pp. 17-37.

Kanjanapan, Wilawan.1989. The Asian-American Traditional Household in Frances K. Goldscheider and Calvin Goldscheider (eds.) Ethnicity and the New Family Economy. Boulder, CO: Westview Press. Pp. 39-55.

Kobrin, Frances. 1978.The Ethnic Factor in Family Structure and Mobility. Cambridge, MA: Ballinger Publishing Co.

Kobrin, Frances and Calvin Goldscheider.1982. "Family Extension or Nonfamily Living: Life Cycle, Economic and Ethnic Factors," Western Sociological Review 13(1): 103-118.

Menard, Scott. 1995. Applied Logistic Regression Analysis. Series/Number 07106. Thousand Oaks, CA: Sage Publications.

Mitchell, Barbara, A. 1994. "Family Structure and Leaving the Nest. A Social Resource Perspective," Sociological Perspectives 37: 651-671.

Mitchell, Barbara, A. 1998 "Too Close for Comfort? Parental Assessments of "Boomerang Kid" Living Arrangements," Canadian Journal of Sociology 23 (1): 21-46.

Mitchell, Barbara A. and Ellen M. Gee. 1996. "' 'Boomerang Kids' and Midlife Parental Martial Satisfaction," Family Relations 45 (October): 442448.

Mitchell, Barbara A, Andrew V. Wister and Thomas K. Burch. 1989. "The Family Environment and Leaving the Parental Home," Journal of Marriage and the Family 51: 605-613.

Noivo, Edite A. 1997. Inside Ethnic Families: Three Generations of Portuguese-Canadians. Montreal: McGill-Queen's University Press.

Settersten, Richard A., Jr. 1998. "A Time to Leave Hone and a Time Never to Return? Age Constraints on the Living Arrangements of Young Adults," Social Forces 76 (June): 1373-1400. 
Veevers, Jean E., Ellen M. Gee and Andrew V. Wister. 1996. "Home Leaving Age Norms: Conflict or Consensus? "The International Journal of Aging and Human Development 43 (4): 277-295.

Veevers, Jean E. and Barbara A. Mitchell. 1998. "Intergenerational Exchanges and Perceptions of Support Within 'Boomerang Kid' Family Environments," International Journal of Aging and Human Development 46(2): 91-108.

Ward, Russell A. and Glenna Spitze. 1992. "Consequence of Parent-adult Child Co-Residence: A Review and Research Agenda," Journal of Family Issues 13 (December): 553-572.

White, Lynn. 1994. "Coresidence and Leaving Home: Young Adults and Their Parents," Annual Review of Sociology 20: 81-102.

White, Lynn K. And Stacy J. Rogers. 1997. "Strong Support But Uneasy Relationships: Coresidence and Adult Children's Relationships with Their Parents," Journal of Marriage and the Family 59 (February): 6276.

Wister, Andrew V., Barbara A. Mitchell, and Ellen M. Gee. 1997. "Does Money Matter? Parental Income and Living Arrangement Satisfaction Among "Boomerang" Children During Co-residence," Canadian Studies in Population 24 (2): 125-145.

Zhou, Min and Carl L. Bankston, III. 1994. "Social Capital and the Adaptation of the Second Generation: the Case of the Vietnamese Youth in New Orleans," International Migration Review 28 (Winter): 821-845.

Received February 1999; Revised April 2000 